\title{
Monitoring of Enzymatic Proteolysis Using Self-Assembled Quantum Dot-Protein Substrate Sensors
}

\author{
Aaron R. Clapp, ${ }^{1,2}$ Ellen R. Goldman, ${ }^{3}$ H. Tetsuo Uyeda, ${ }^{1,4}$ Eddie L. Chang, ${ }^{3}$ \\ Jessica L. Whitley, ${ }^{5}$ and Igor L. Medintz ${ }^{1}$ \\ ${ }^{1}$ Division of Optical Sciences, Code 5611, U.S. Naval Research Laboratory, 4555 Overlook Ave, SW, Washington, DC 20375, USA \\ ${ }^{2}$ Department of Chemical \& Biological Engineering, Iowa State University, Ames, IA 50011, USA \\ ${ }^{3}$ Center for Bio/Molecular Science and Engineering, Code 6900, U.S. Naval Research Laboratory, 4555 Overlook Ave, SW, Washington, \\ DC 20375, USA \\ ${ }^{4}$ Promega Biosciences, Inc., 277 Granada Dr., San Luis Obispo, CA 93401, USA \\ ${ }^{5}$ Center for Biomedical Genomics, George Mason University, Fairfax, VA 22030, USA
}

Correspondence should be addressed to Igor L. Medintz, igor.medintz@nrl.navy.mil

Received 9 May 2008; Accepted 28 June 2008

Recommended by Francesco Baldini

\begin{abstract}
We have previously utilized hybrid semiconductor quantum dot- (QD-) peptide substrates for monitoring of enzymatic proteolysis. In this report, we expand on this sensing strategy to further monitor protein-protease interactions. We utilize QDs selfassembled with multiple copies of dye-labeled proteins as substrates for the sensing of protease activity. Detection of proteolysis is based on changes in the rate of fluorescence resonance energy transfer (FRET) between the QDs and the proximal dye-labeled proteins following protein digestion by added enzyme. Our study focused on two representative proteolytic enzymes: the cysteine protease papain and the serine protease endoproteinase K. Analysis of the enzymatic digestion allowed us to estimate minimal values for the enzymatic activities of each enzyme used. Mechanisms of enzymatic inhibition were also inferred from the FRET data collected in the presence of inhibitors. Potential applications of this technology include drug discovery assays and in vivo cellular monitoring of enzymatic activity.
\end{abstract}

Copyright (c) 2008 Aaron R. Clapp et al. This is an open access article distributed under the Creative Commons Attribution License, which permits unrestricted use, distribution, and reproduction in any medium, provided the original work is properly cited.

\section{INTRODUCTION}

Proteases havecritical functions in many normal and aberrant biochemical processes that occur at the cellular and organismal levels [1]. This includes roles in the development of tissues and organs, regulation of wound healing, necrosis, and apoptosis [1-4]. Proteases also play active roles in diseases, such as stroke, cancer, and over 50 genetic disorders [2, 5-8]. Furthermore, many infectious microorganisms, including viruses and bacteria, use proteases as essential virulence factors [2, 9-12]. In combination, these properties indicate that proteases are important research and pharmaceutical targets that require the development of improved sensitive techniques to monitor their activity both in vivo and in vitro.

Most assays designed to monitor protease activity rely on detecting the cleavage or digestion of an appropriate substrate, such as a peptide or a protein, recognized by the target protease $[13,14]$. For signal transduction, these assays often use changes in fluorescence resonance energy transfer (FRET) between two distinct fluorophores attached to the opposite ends of the substrate, following interactions with the protease [14-16]. The fluorophores used in these assays are usually organic dyes or fluorescent proteins. Alternatively, when the assay requires a complete intact native protein substrate rather than a minimal peptide sequence, a combination of other analytical techniques such as radioactive labeling, gel electrophoresis, or mass spectral analysis are used $[17,18]$. Each of these techniques has limitations, however. For example, fluorescent proteins and organic dyes used in FRET-based detection have absorption and emission spectra that are closely spaced (small Stoke's shifts) which invariably leads to donor-acceptor signal cross-talk [19]. Successful implementation of this detection scheme 
often requires sophisticated instrumentation and complex data analysis. Conventional organic fluorophores can also be $\mathrm{pH}$ sensitive and photolabile. Radioactive isotopes, on the other hand, are increasingly difficult to work with due to safety and disposal problems, while mass spectrometry requires complex instrumentation and time-consuming sample preparation and analysis.

It has recently been demonstrated that luminescent QDs are effective fluorophores for use in a variety of biosensing configurations (e.g., immunoassay labels or cellular probes) to detect specific analytes $[20,21]$. Along with high quantum yield and pronounced photostability as compared to conventional dyes or fluorescent proteins, QDs also offer several unique advantages as FRET donors [22, 23]. These include the ability to tune the spectral overlap with a particular acceptor through choice of QD donor emission along with the option of exciting the system at a wavelength far removed from the acceptor absorption peak, thus reducing direct excitation of the acceptor. A central QD can interact with multiple acceptors within a single QD-bioconjugate, which increases the overall FRET efficiency due to multiple energy transfer interactions per conjugate [23, 24]. Additionally, one excitation source can be used with almost any QD which, along with a wide choice in emission colors, allows compatibility with almost any instrumental configuration. We and other groups have applied QD-based FRET to the detection of soluble molecules, such as the nutrient sugar maltose, the explosive trinitrotoluene, and specific DNA segments [25-29]. Cumulatively, these demonstrations show the potential of QD-protein bioconjugates for improved FRET-based biosensing including in proteolytic monitoring $[19,30]$.

We have previously reported that the use of designer peptide substrates conjugated to QDs, where control over the average number of peptides attached per QD along with their sequence, allowed us to specifically detect the activity of various proteases including caspase-1, thrombin, chymotrypsin, and collagenase [31]. Proteolytic assays were carried out under both excess enzyme and excess substrate conditions allowing quantitative monitoring of protease activity and providing insight into mechanisms of enzymatic inhibition. To demonstrate the potential for these bioconjugates, a number of inhibitory compounds were tested against the QD-thrombin-specific peptide substrate in a pharmaceutical screening assay. However, as substrates, peptides are limited due to their small size which in turn limits their potential conformations and full protein-on-protein interactions are in many cases more reflective of biochemical interactions and true cellular context. In this report, we expand this QD-based sensing strategy to include full proteins as substrates. We demonstrate FRET-based monitoring of protein digestion by proteolytic enzymes, namely, proteinase $\mathrm{K}$ and papain, using QD-protein conjugates as substrates (see Figure 1). The enzymatic digestion data were analyzed in a manner that allowed us to estimate the minimal values for enzymatic activity or velocity for each enzyme used within that assay. Mechanisms of enzymatic inhibition were also inferred from assays performed in the presence of specific inhibitors.

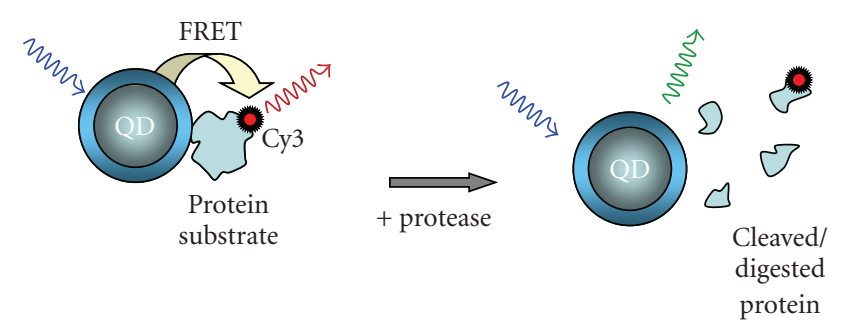

(a)

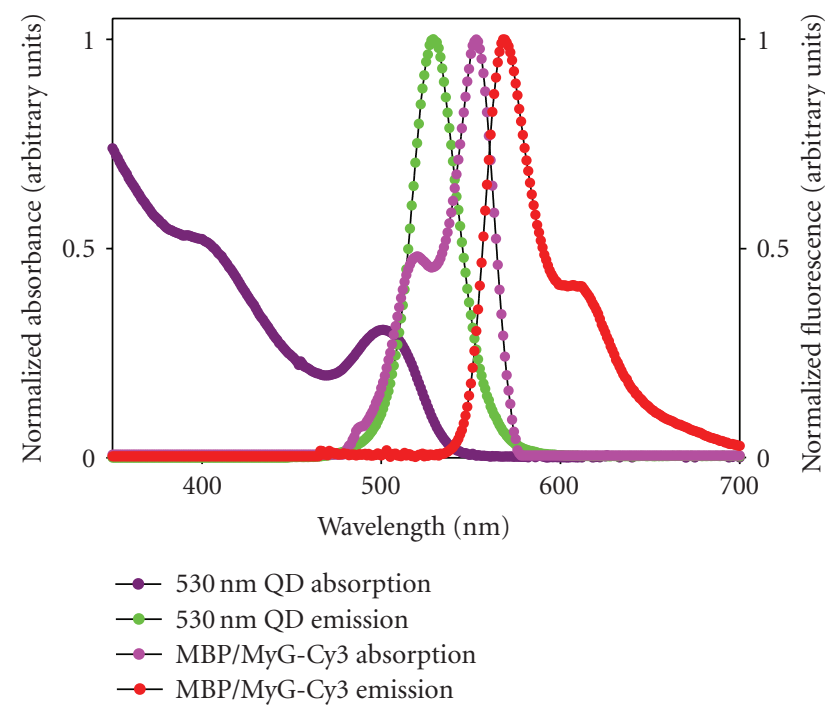

(b)

FIGURE 1: (a) Schematic depiction of the QD-protein bioconjugates and the change in PL signal following interactions with target protease. Self-assembly of Cy3-labeled proteins on the QDs induces efficient FRET between the QD and dye. Only one protein is shown for brevity, not to scale. Added protease cleaves/digests the protein and changes the FRET signature. (b) Normalized absorption and emission spectra for Cy3-labeled $\mathrm{MyG}$ (Cy3 QY $=0.20, \varepsilon \cong$ $\left.150,000 \mathrm{M}^{-1} \mathrm{~cm}^{-1}, \lambda_{\mathrm{exc}}=555 \mathrm{~nm}, \lambda_{\mathrm{em}}=570 \mathrm{~nm}\right)$ and $530 \mathrm{~nm}$ emitting QDs $\left(\mathrm{QY} \cong 0.20\right.$, QD-Cy3 $\left.R_{0} \cong 52.5 \AA\right)$. Note: the QD absorbance is not normalized.

\section{EXPERIMENTAL}

\subsection{QD synthesis}

CdSe-ZnS core-shell QDs employed in this study were synthesized step-wise by reacting organometallic precursors at high temperature in coordinating solvent mixtures of trioctyl phosphine/trioctyphophine oxide (TOP/TOPO) and amines. This synthesis scheme is detailed in previous reports [32-36] and consistently provides nanocrystals with low polydispersity and high quantum yields (QYs). Water-soluble QDs were prepared by exchanging the native TOP/TOPO surface capping ligands with dihydrolipoic acid (DHLA) [35]. Two QD populations with emission maxima centered at $520 \mathrm{~nm}$ and $530 \mathrm{~nm}$ were used;they both have favorable spectral overlap with the Cy3 dye absorption (see Figure 1). 


\subsection{Protein purification and labeling with dye acceptor}

Proteins used in this study include maltose binding protein and apomyoglobin. Maltose binding protein (MBP, MW $44 \mathrm{kDa}$ ) appended with a C-terminal pentahistidine (His ${ }_{5}$ ) sequence and expressing a unique cysteine at residue 95C as well as apomyoglobin ( $\mathrm{MyG}, \mathrm{MW} \sim 17 \mathrm{kDa}$ ) expressing a unique cysteine at residue $116 \mathrm{C}$ and appended with a C-terminal $\mathrm{His}_{6}$ were prepared as described previously [37]. Both MBP95C and MyG116C were labeled with maleimideactivated $\mathrm{Cy} 3$ dye (Amersham Biosciences, Piscataway, $\mathrm{NJ}$ ); following purification, this yielded average dye-to-protein $(\mathrm{D} / \mathrm{P})$ ratios of $\sim 1$ as expected $[25,38]$.

\subsection{Assembly and characterization of the dye-labeled QD-protein nanosensors}

We first characterize the FRET properties of the QDprotein substrates used in this study. The QD-MyG-Cy3 assemblies used as substrates for papain assays were prepared by mixing $20 \mathrm{pmol}$ of DHLA-capped QDs with increasing concentration of MyG-Cy3 (increasing Cy3-to-QD ratio, $n)$ in $100 \mu \mathrm{L} 10 \mathrm{mM}$ sodium tetraborate buffer $\mathrm{pH} 8.5$ and letting the solution incubate for 20-30 minutes; this corresponds to a concentration of $0.2 \mu \mathrm{M}$ QDs. Similarly, the QD-MBP-Cy3 nanoassemblies targeting proteinase $\mathrm{K}$ were prepared in $10 \mathrm{mM}$ HEPES buffer $\mathrm{pH} 8.0$ (also at $0.2 \mu \mathrm{M}$ QDs). Aliquots of these solutions were then loaded in a microtiter plate wells and the fluorescence spectra were collected at each dye-to-QD ratio for the two sets of assemblies. Data on the FRET efficiency (derived from donor quenching) versus average number of dye-to-QD ratio, $n$, were used to construct standard/calibration curves, establishing a one-to-one functional relationship between the measured FRET efficiency and the number of labeledproteins per QD-conjugate for each system. These standard curves were subsequently used to convert changes in the FRET efficiency measured for conjugates interacting with the targeted enzyme into enzymatic activity (see below).

The data for FRET efficiency versus $n$ were also analyzed within the Förster formalism to determine values for centerto-center (QD-to-dye) separation distance $r$ and to gain insights into the conjugate structure using the following expression (developed for a centro-symmetric QD-proteindye conjugate) [23]:

$$
r=\left(\frac{n\left(1-E_{n}\right)}{E_{n}}\right)^{1 / 6} R_{0} .
$$

$E_{n}$ is the FRET efficiency and $R_{0}$ designates the Förster radius corresponding to $E_{n=1}=0.5$ [19]. $R_{0}$ is expressed as

$$
R_{0}=9.78 \times 10^{3}\left[\kappa^{2} n_{D} Q_{D} I\right]^{1 / 6},
$$

where $n_{D}$ is the refractive index of the medium, $Q_{D}$ is the PL quantum yield of the donor in the absence of acceptor, $I$ is the integral of the spectral overlap, and $\kappa^{2}$ is the dipole orientation factor. A $2 / 3$ value for $\kappa^{2}$ corresponding to a random dipole orientation was shown to be appropriate for our self-assembled QD-protein-dye and QD-peptide-dye conjugates, as detailed in [23]. Experimentally, the FRET efficiency $E$ was determined using

$$
E_{n}=\frac{\left(F_{D}-F_{D A}\right)}{F_{D}},
$$

where $F_{D}$ and $F_{D A}$ designate the fluorescence intensities of the donor alone and the donor in the presence of acceptor(s), respectively [19].

The QD-MyG-Cy3 substrates used for assaying papain activity were prepared by mixing $20 \mathrm{pmol}$ of DHLA-capped QDs (emission at $520 \mathrm{~nm}$ ) with $60 \mathrm{pmol}$ of MyG-Cy3 (ratio QD:MyG of 1:3) in sodium tetraborate buffer $\mathrm{pH} 8.5$ and let incubate for 20-30 minutes; for this initial stock solution $E_{n=3} \approx 0.84$. Aliquots of these solutions were then loaded in a microtiter plate wells. Carica papaya (Sigma, MW $\sim 23 \mathrm{kDa}$, EC 3.4.22.2, with specific activity of 3.3 units/mg powder) dissolved in borate buffer at the desired concentrations was added to each well (to a total of $100 \mu \mathrm{L}$ of reaction solution) and allowed to react with the QD conjugates for 7-10 minutes at room temperature. The final substrate concentration was $0.2 \mu \mathrm{M}$ QDs (and $0.6 \mu \mathrm{M}$ MyG-Cy3). The PL emission spectra were then collected at each enzyme concentration. For the papain inhibition assay, three types of inhibitors were added to the appropriate wells at the indicated concentration before fluorescence data collection: $\alpha$-iodoacetamide (AIA, Sigma-Aldrich, St. Louis, Miss), a known noncompetitive inhibitor of proteases, was added at $10 \mathrm{mM}$ concentration and functioned as a positive control; Pepstatin A (Sigma), a peptidyl inhibitor of acid proteases and known to have no specificity for cysteine proteases such as papain, was used at the recommended concentration of $1 \mu \mathrm{M}$ (negative control); and leupeptin (Sigma), a peptidyl inhibitor of cysteine protease known to function as a competitive inhibitor was tested at $100 \mu \mathrm{M}$ and $300 \mu \mathrm{M}$ concentrations.

For substrates used in assaying the activity of proteinase K, a stock solution of QD-MBP-Cy3 conjugates was prepared at a ratio $n=5$ corresponding to an initial FRET efficiency $E_{n=5}=0.6$; aliquots of this solution were loaded into the wells of a microtiter plate. Proteinase $\mathrm{K}$ (Pro-K, MW $\sim 27 \mathrm{kDa}$, EC 3.4.21.64, specific activity of 30 units/mg protein, New England Biolabs, Beverly, Mass) diluted in $10 \mathrm{mM}$ HEPES buffer at $\mathrm{pH} 8.0$ was added to the wells at several concentrations (to a total of $100 \mu \mathrm{L}$ of reaction solution) and allowed to react for 7-10 minutes at room temperature before fluorescence spectra collection and analysis. Final QD-MBP (QD-substrate) concentration in each well was $0.2 \mu \mathrm{M}$ of QDs. For the Pro-K inhibition assay, $426 \mu \mathrm{M}$ kanamycin (Sigma, St Louis, Miss) was added to the appropriate wells along with the enzyme followed by PL data collection, at the same QD-MBP (QD-substrate) concentration. All assays were performed at least in triplicate with standard deviations shown where appropriate.

Fluorescence spectra were collected on a Tecan Safire Dual Monochromator Multifunction Microtiter Plate Reader (Tecan US, Research Triangle Park, NC). Samples were excited at $300 \mathrm{~nm}$ and either full PL emission spectra or 
partial integration from spectral windows (width $\sim 2.5 \mathrm{~nm}$ ) at the peak emission of QD and dye was carried out.

\subsection{Enzymatic data analysis}

Changes in the FRET efficiencies collected for the series of enzyme concentrations were then compared to the calibration curves to derive an estimate for the ratio of intact proteins per QD-conjugate left in the solution following the reaction. By comparing to the fluorescence data of the initial stock solution, a measure for the amount (concentration) of digested substrate is determined. Enzymatic activity rates or "velocities" were then deduced by converting the amount of digested proteins $[\mathrm{P}]$ to a concentration of digested substrate per unit time $(\mathrm{d}[\mathrm{P}] / \mathrm{dt})$. In this study, we define proteolytic (or enzymatic) velocity in units of molar protein cleaved per minute. The proteases utilized in this study recognize and cleave many sequences in each of the protein substrates, however, it is only the digestion of the specific dye-labeled segment/region of a protein substrate that is the key transduction event. Although we cannot observe many of the "silent" cleavage events, by treating the observed FRET changes from corresponding digestion as a single event and correlating it to molar protein units, we are able to quantitatively estimate a minimal value for enzymatic activity in these assay formats. In essence, we are estimating the lower boundary of enzymatic velocity as actual velocity will always be at least this value or higher. Further, we use the terms maximum velocity or $V_{\max }$ and apparent maximum velocity or $V_{\max }^{\mathrm{app}}$ to describe the highest measured activity of an enzyme in the absence or presence of an inhibitor in an assay. Within a particular assay, fitting of the activity data curve allows us to derive the asymptote, providing an estimate of the enzymatic turnover rate or velocity. Again these values represent a minimal or lower boundary. A broad range of enzyme concentrations was explored. Starting from a concentration where a near complete substrate digestion is expected to occur within an allotted reaction time of 20 minutes (stock solution) [39], a serial dilution over several orders was prepared and subsequently used in the digestion experiments. By limiting the digestion experiments to concentrations far enough below that of the stock solution and using a reaction time of $\sim 7-10$ minutes, we ensured that initial rates were always measured within the experimental conditions.

\section{RESULTS AND DISCUSSION}

As with the previous QD-peptide substrates, the QDprotein conjugation method used for this study is based on metal-affinity-driven self-assembly. This process is initiated by interactions between the terminal polyhistidine tract appended at the $\mathrm{C}$ - or $\mathrm{N}$-terminus of the protein and the metallic surface of DHLA-capped CdSe-ZnS QDs. In a recent study, we have demonstrated that such conjugation is not necessarily driven by electrostatic attractions, since it can be implemented using QDs capped with polyethylene glycol- (PEG-) terminated DHLA ligands (neutral DHLAPEG ligands), provided that the polyhistidine sequence itself is well exposed and available; this permits the His-tract to interdigitate with the DHLA-PEG ligands and directly access the $\mathrm{ZnS}$ surface of the nanocrystals for strong binding [40]. Further, our study showed that these interactions are stable with an anticipated dissociation constant of $\sim 1-10 \mathrm{nM}$. Metal-affinity-driven self-assembly provides stable and functional conjugates within 10-15 minutes of reagent mixing [31]. This conjugation method also offers a unique advantage by allowing control over the average number of attached protein/peptides per QD and potentially the orientation of proteins or peptides within the QD-bioconjugates [23, 41-43].

\subsection{QD-protein assemblies and FRET efficiency}

Figure 2(a) shows the composite PL spectra collected from solutions of QD-MyG-Cy3 (520 nm QDs) conjugates for increasing Cy3-to-QD ratio, $n$. Figure 2(b) shows a plot of the FRET efficiency (together with the QD PL loss) versus $n$; this constitutes the standard curve introduced above. The efficiency values were calculated from the QD PL loss (after deconvoluting the composite spectra shown in Figure 2(a)). Similar data for the raw spectra, QD PL loss and FRET efficiency were collected for the QD-MBP-Cy3 (530 nm QDs) assemblies (data not shown). The efficiency data were further analyzed using (1) and (2) to extract estimates for the center-to-center separation distance, $r$, for the two sets of QD-protein assemblies. Due to the high FRET efficiencies measured for these systems, heterogeneity in the conjugate valence was accounted for when fitting the data to the Förster formalism using Poisson distributions as detailed in [41].Center-to-center QD-dye separation distances determined from the $520 \mathrm{~nm}$ QD-MyG-Cy3 $\left(R_{0} \cong 51 \AA\right)$ and $530 \mathrm{~nm}$ QD-MBP-Cy3 $\left(R_{0} \cong 52.5 \AA\right)$ assemblies were of 51 $\pm 2 \AA$ Aand $65 \pm 3 \AA$, respectively. The difference in distances derived above is primarily due to differences in the protein dimensions and labeling site, since $520 \mathrm{~nm}$ and $530 \mathrm{~nm}$, QDs have hard radii that differ by only $\sim 2-4 \AA[22,23]$. These values are consistent with the protein dimensions, as anticipated from their respective molecular weights, the crystallographic data, and the specific dye-labeled residues in the protein sequences $[44,45]$. The value measured for the QD-MBP-Cy3 assemblies is in agreement with previous distances measured for dye-labeling of this particular residue (95C) $[23,43]$. In contrast, MyG is a relatively small protein (MW $\sim 17 \mathrm{kDa}$ compared to MW $\sim 44 \mathrm{kDa}$ for MBP), which results in a shorter separation distance and produces higher FRET efficiencies even at small dye-to-QD ratio; this was reflected by $\sim 50 \%$ loss in QD PL at $n=1\left(r \sim R_{0}\right.$ for this QD-dye pair). We should emphasize that calibration curves using either FRET efficiency versus $n$, or dye-to-QD $\mathrm{PL}$ ratios versus $n$, can be used to obtain information on the enzyme kinetic parameters and inhibition. Both forms provide similar information on the enzyme kinetics, as we have recently shown for QD-peptide substrates [31].

\subsection{QD-based papain and proteinase-K sensing}

In this study, we focused on two representative proteases, papain and proteinase-K. Papain is a prototypical cysteine 


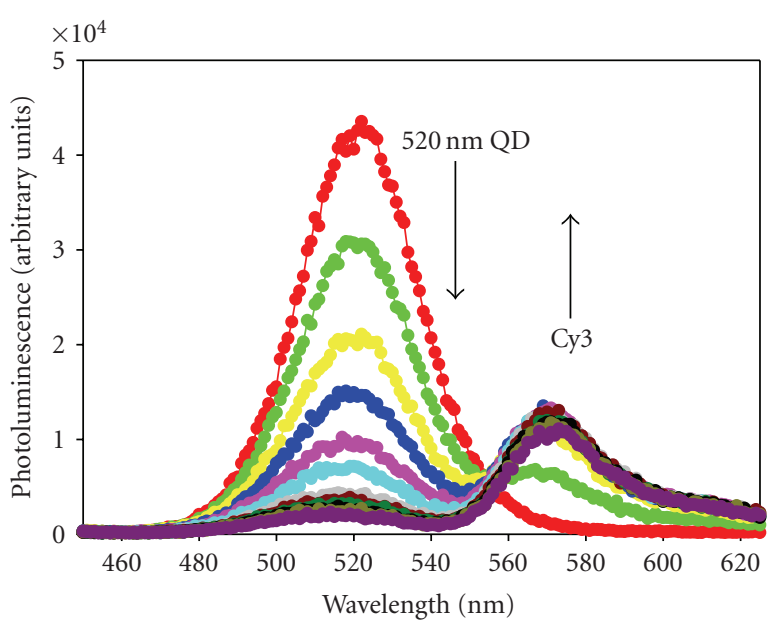

Ratio MyG-Cy3/QD

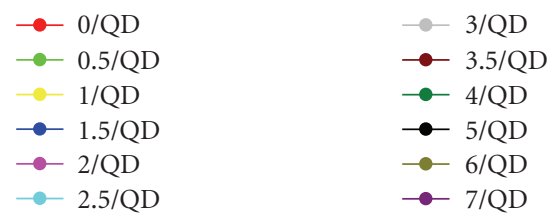

(a)

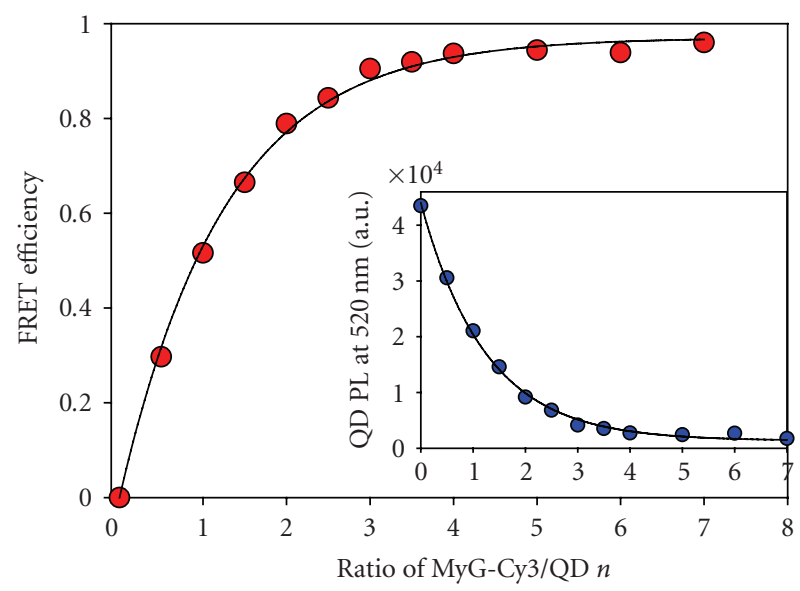

(b)

Figure 2: (a) Composite PL spectra showing $520 \mathrm{~nm}$ QDs selfassembled with an increasing number of MyG116C-Cy3 per QDconjugate. (b) FRET efficiency versus MyG-Cy3-to-QD ratio $n$, derived from the deconvoluted integrated QD PL intensity. Inset shows the corresponding PL intensity at $520 \mathrm{~nm}$ versus $n$. Similar data were collected for the $530 \mathrm{~nm}$ QD-MBP-Cy3 assemblies.

protease that cleaves the peptide bonds of basic amino acids, leucine and glycine, as well as hydrolyzes esters and amides. It is commonly used for extracting fragments from whole antibodies, dissociating cells from surfaces or tissues, and as a meat tenderizer [46]. Proteinase K (endopeptidase K or Pro$\mathrm{K}$ ) is a non-specific serine protease isolated from the mold Tritirachium album limber, with a high specific activity; it is well suited for experiments requiring short digestion times. Pro-K belongs to the superfamily of subtilisin proteases and can hydrolyze both native and denatured proteins.
Further, Pro- $\mathrm{K}$ is stable across a wide range of $\mathrm{pHs}$ and temperatures and its activity is not affected by the presence of chelating agents such as EDTA. It has found use in an array of biotechnological applications, including the digestion of proteins and inactivation of nucleases (e.g., isolation of mRNA and high molecular weight DNA) and as a tool for the purification of target nucleic acid material from contaminating proteins. Pro-K has also been used for the production of characteristic protein fragments that can be used in protein structure/function studies $[47,48]$. In addition, Pro-K can inactivate other enzymes and can thus be used as a potential inhibitor. Papain was tested with $520 \mathrm{~nm}$ QD-MyG-Cy3 and Pro-K was tested with $530 \mathrm{~nm}$ QD-MBPCy3 substrates, respectively.

Addition of the protease to a solution of QD-protein conjugates digests/cleaves the protein substrate, allowing the dye acceptor to diffuse away from the QD surface. This systematically alters the FRET efficiency. Monitoring changes in the rate of FRET as a function of enzyme concentration over a given reaction time forms the basis of our assays. Comparing those changes against the standard curves can provide estimates of the amount of digested substrate per unit reaction time (i.e., velocity reported in molar concentration of MyG or MBP cleaved per min). In choosing the starting QD-protein solution for mixing with the enzyme, we refer to the FRET calibration curve where selection of dye-to-QD ratio satisfies two criteria: (1) high initial FRET efficiency, followed by (2) a large change in the measured FRET efficiency upon interaction with the target enzyme, which would result in a broad dynamic range of accessible velocities. As such, we chose an ensemble ratio of $3 \mathrm{MyG}-\mathrm{Cy} 3$ per QD for assays targeting papain and 5 MBP-Cy3 per QD for assays targeting Pro-K; this corresponds to $E_{n} \approx 0.6$ and 0.84 for the QD-MBP-Cy3 and QD-MyG-Cy3 assemblies, respectively (see Figure 2). Such ratios should provide large changes in the FRET efficiency upon cleavage of the QD-bound substrate. PL emission from solutions containing equivalent amounts of free proteindye (accounting for direct-acceptor excitation contribution) were collected and subtracted from the composite spectra before data analysis (data not shown).

For the inhibition of papain, we tested the protease activity in the presence of AIA at a strong inhibitory concentration, as well as an inhibitor known not to affect papain activity, Pepstatin A. AIA is an alkylating reagent specific to the cysteine/histidine residues in proteins and is commonly used as an irreversible enzyme and protease inhibitor [49]. Pepstatin A (sequence: Ac-Val-Val-Sta-AlaSta, where Ac $=$ acetyl and Sta $=3$ S, $4 S-4$-amino-3-hydroxy6-methylheptanoic acid) is a peptidyl inhibitor of acid proteases (aspartyl peptidases), including pepsin, renin, bovine chymosin, and protease B. It is highly selective and known not to inhibit serine or cysteine proteases such as papain (i.e., negative control). We also explored papain inhibition by leupeptin at two different concentrations. Leupeptin is a peptidyl (Acetyl-Leu-Leu-Arg-aldehyde) inhibitor of serine and cysteine proteases. To investigate the inhibition of Pro$\mathrm{K}$, we used kanamycin at $426 \mu \mathrm{M}$. Kanamycin is generally used as a broad-spectrum aminoglycoside-antibiotic as it 
inhibits ribosomal protein translocation among other complex inhibitory functions [50]. We should stress that in choosing the initial concentration of a particular inhibitor, we referred to the recommended experimental protocols specific for each enzyme-inhibitor pair provided by the manufacturer. Therefore, the inhibitor concentration used in each case is a priori expected to effectively alter the activity of the target enzyme.

Figure 3(a) shows plots of the estimated velocity $(\mathrm{d}[\mathrm{P}] / \mathrm{dt})$ versus increasing concentration of papain alone (blue squares, $V_{\max }=9 \mathrm{nM} / \mathrm{min}$ ), papain in the presence of $10 \mathrm{mM}$ of AIA (red circles, $V_{\max }^{\mathrm{app}}=3.4 \mathrm{nM} / \mathrm{min}$ ), and papain in the presence of $1 \mu \mathrm{M}$ of pepstatin (purple triangles, $\left.V_{\max }^{\mathrm{app}} \sim 9 \mathrm{nM} / \mathrm{min}\right)$. The observed data and significant decrease in maximum velocity indicates that the AIA presence directly affects the enzymatic activity. This finding is consistent with AIA's function as a nonspecific alkylating agent which would modify both the proteins reaction site and other allosteric residues. In comparison, essentially no significant changes were measured in the presence of pepstatin. Figure 3(b) shows plots for the velocity $(d[P] / d t)$ for the assay using QD-MBP-Cy3 substrate reacted with Pro-K alone (blue curve, $V_{\max }=5.6 \mathrm{nM}$ ) or with Pro-K mixed with kanamycin inhibitor (red curve, $V_{\max }^{\mathrm{app}}=2.3 \mathrm{nM}$ ). The values extracted for $V_{\max }$ are about an order of magnitude smaller than those measured for papain, a property attributable to the much higher specific activity of Pro-K (Pro-K activity is 30 units/mg compared to 3.3 units/mg for papain). Addition of kanamycin, a broad ranging antibiotic agent derived from Streptomyces kanamyceticus, to the assay solution results in a substantial decrease in the $V_{\max }$ (by a factor of $\sim 2.5$ ) similar to what was observed for papain assayed in the presence of AIA.

\subsection{Kinetics of enzymatic inhibition}

The nature of the changes in the velocity versus enzyme concentration observed upon addition of inhibitors (shown in Figure 3) can reflect the mechanism of inhibition involved and potentially its kinetics. Lineweaver-Burk (L-B) analysis, which uses a plot of the inverse velocity, $1 / V$, against inverse enzyme concentration, $1 /[E]$, is commonly employed to identify the mechanism(s) of enzymatic inhibition from both the changes in axis intercept values and the relative positions of the inhibited plots [51]. The Lineweaver-Burk analysis applied to the assay results shown in Figure 3 yields similar behaviors for the QD-MyG reacting with papain-AIA and for QD-MBP reacting with Pro-K-kanamycin (see plots in Figure 4). Within the Lineweaver-Burk plot, the $y$-axis intercept is equal to $1 / V_{\max }$ and the results confirm that the inhibitors are altering the maximum velocity $\left(V_{\max }^{\mathrm{app}} \neq V_{\max }\right)$. The appearance of these types of changes in an L-B plot also suggests that a mixed noncompetitive inhibition dominates the interactions for these systems in our assay format [52]. This confirms what is anticipated based on the structure and function of AIA, which would alter the proteases' binding site and other potentially allosteric sites. Due to the complexity of its function, the exact mechanism of Kanamycin inhibition of Pro-K is, however, not yet fully known.

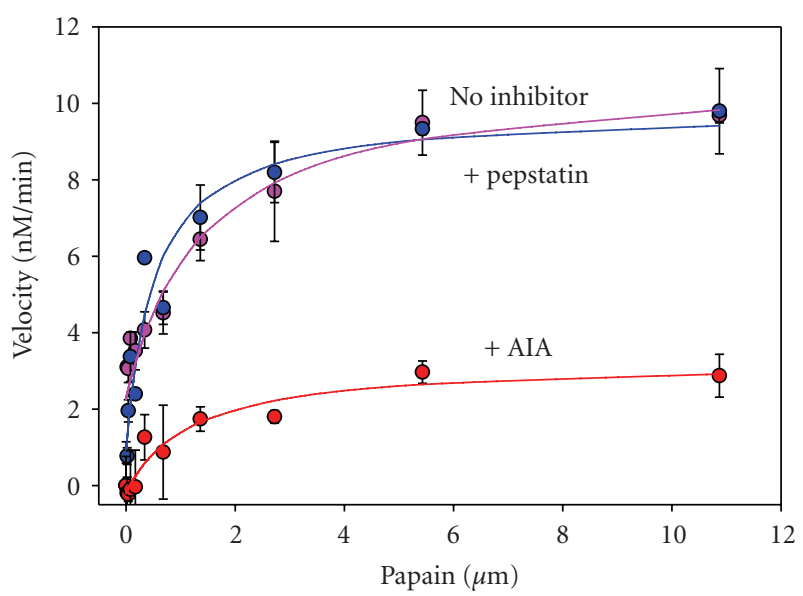

(a)

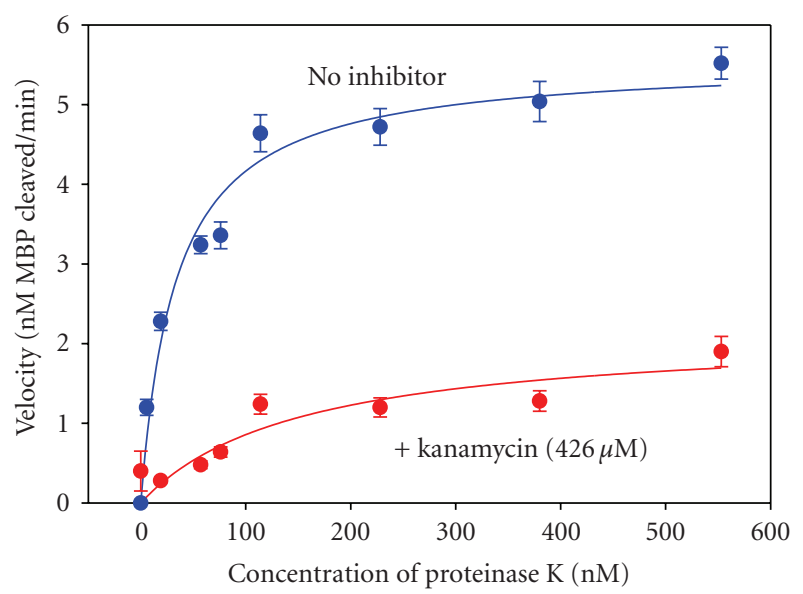

(b)

FIGURE 3: (a) Results from assaying an increasing concentration of papain against a constant amount of QD-MyG-Cy3 in the absence (blue squares) and in presence (red circles) of $10 \mathrm{mM}$ AIA (red squares) or $1 \mu \mathrm{M}$ pepstatin (purple triangles) inhibitors. Changes in FRET efficiency were converted to activity (nM MyG substrate cleaved $/ \mathrm{min}$ ) as described in the text. (b) Velocity versus increasing Pro-K concentration assayed against a fixed QD-MBP-Cy3 substrate concentration in the absence (blue squares) and presence of $426 \mu \mathrm{M}$ of kanamycin inhibitor (red circles). Solid lines are best fits to the data to aid the eye.

\subsection{Leupeptin inhibition}

Leupeptin is a known competitive inhibitor of serine and cysteine proteases and its recommended effective range is $10-100 \mu \mathrm{M}$ for bacterial cell lysates (Sigma-Aldrich.com). Initial assaying of the QD-Myg-papain system at both 100 and $300 \mu \mathrm{M}$ resulted in modest changes in $V_{\max }$ while the overall shapes of the curves essentially remained the same which is indicative of a competitive inhibition process (see Figure 5(a)) [52]. We opted to confirm the inhibitory effects in an alternate format by adding increasing concentrations of leupeptin (mixed with papain) to solutions containing QDMyG substrates. For this, we fixed the substrate concentration at $0.2 \mu \mathrm{M}$ QDs (with $3 \mathrm{MyG}-\mathrm{Cy} 3$ per conjugate), and 


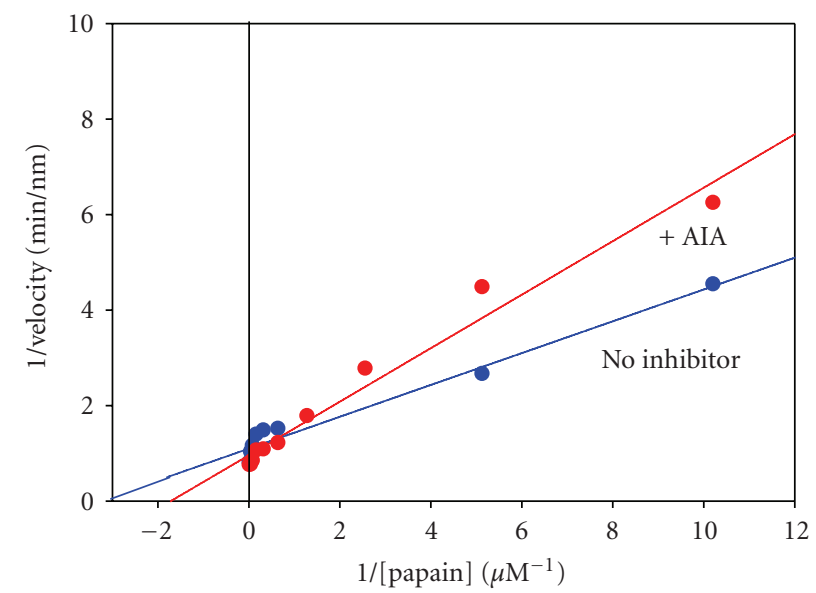

(a)

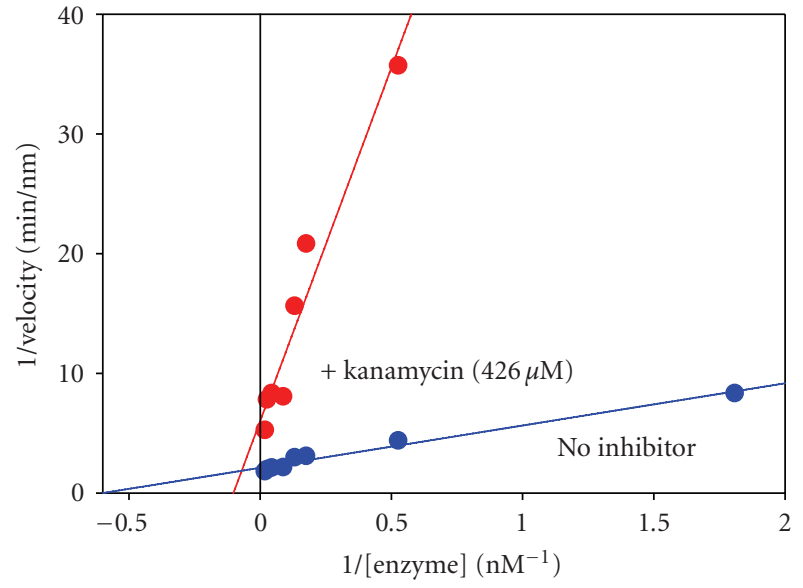

(b)

FIGURE 4: (a) Lineweaver-Burk (L-B) double reciprocal plots of the data shown in Figure 3 for the assay using QD-MyG to test the inhibitionactivity of papain-AIA; papain only (blue squares) and papain plus AIA inhibitor (red circles). (b) L-B plots of the data shown in Figure 3(b) assaying for the Pro-K-kanamycin pair; shown are Pro-K only (blue squares) and Pro-K plus kanamycin inhibitor (red circles). Data show that the $V_{\max }$ are affected by the presence of kanamycin inhibitor.

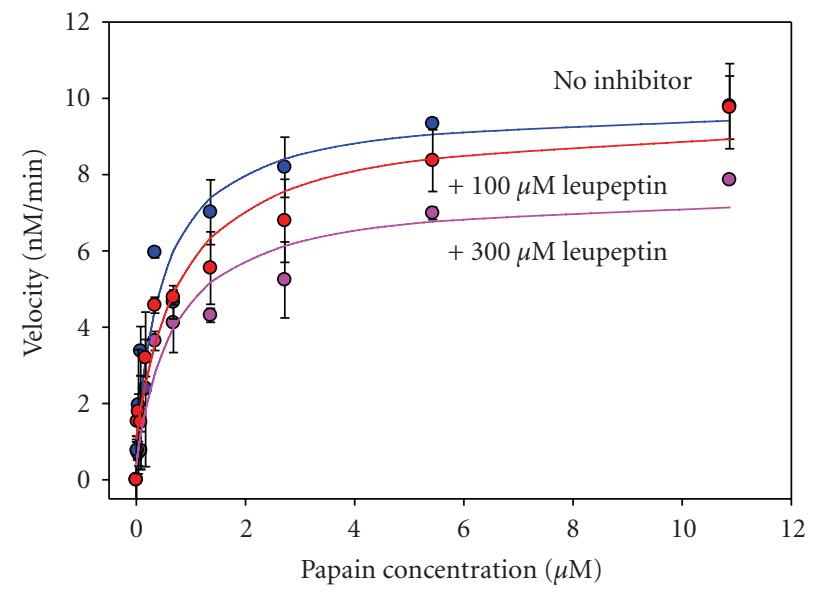

(a)

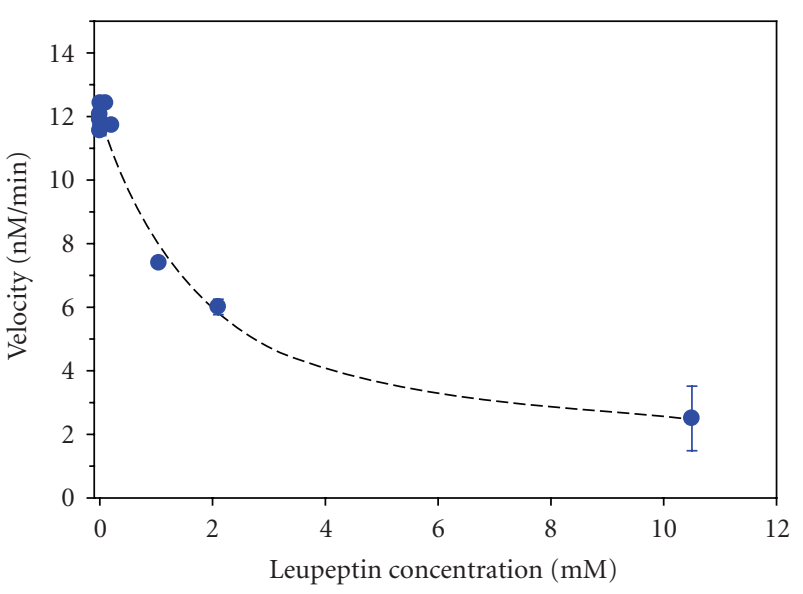

(b)

FIGURE 5: (a) Velocity versus papain enzyme concentration for QD-MyG assayed alone and in the presence of $100 \mu \mathrm{M}$ and $300 \mu \mathrm{M}$ leupeptin. (b) Plot of the velocity versus leupeptin concentration measured using a concentration of papain near saturation. Solid lines are best fits to the data to aid the eye.

maintained a high concentration of papain $(15 \mu \mathrm{M}$, near saturation based on the above results derived in Figure 5(a)), but progressively increased the leupeptin concentration. Using such high papain concentration ensured that for a reasonably small inhibitor concentration we measured velocities near $V_{\max }$ (appropriate for a non-competitive inhibitor). The velocity data collected from these solutions show a progressive decrease with increasing inhibitor concentration and allow us to estimate an inhibitor concentration that corresponds to a significant decrease in activity $(>50 \%)$ of $>2 \mathrm{mM}$ (Figure 5(b)).

Cumulatively, these results confirm a competitive inhibitory process in the assay and indicate that the effective inhibitory concentration of leupeptin on papain is $\sim 20$ times higher than that suggested for cysteine proteases of bacterial origin (as recommended by the manufacturer). However, it should be noted that although papain is a member of the same superfamily of cysteine proteases, it most probably has a different structure and function because it originates from the fruit of a plant. This result also highlights the importance of pretesting any enzyme-inhibitor combination before selecting an effective inhibitory concentration in a targeted application, such as extracting nucleic acids from plants or fruits as opposed to extraction from bacteria.

\section{CONCLUSIONS}

In this report, we expanded on our previous results with QD-peptide substrates and demonstrated the use of luminescent QDs as nanoscaffolds for self-assembling FRET-based 
protein substrates to semiquantitatively detect proteolytic enzyme activity derived from protein-protease interactions. Experiments testing QD-protein substrates in assays with and without added inhibitors showed that enzymatic digestion along with mechanism of inhibition can be inferred from assay results. The current sensing assemblies also benefit from the ability to array multiple copies of dye-labeled proteins around a single QD which serves to both improve FRET efficiency and allow simultaneously interrogation of multiple protein substrates in the same FRET pair by the enzyme (and inhibitor).

A few specific aspects of these sensing assemblies should be clarified. In contrast to our previous studies [23], we do not use additional unlabeled proteins to the QD assemblies. These are usually added as they help ameliorate conjugate heterogeneity caused by Poisson distribution kinetics when self-assembling small ratios of proteins to QDs [31, 41, 42] and to improve the QY of the QD in the conjugate through surface passivation effects $[22,53]$. The error introduced by essentially ignoring heterogeneity and the overall changes in the QY of the conjugates is rather small in comparison with changes in measured FRET efficiencies. Further, the nature of the proteases and the assay formats used only allow us to derive the minimal enzymatic activity and not other values such as the Michaelis constant or turnover number.

Both of the enzymes utilized here can function at a wide range of pH's and with a variety of additives present, and the choice of slightly basic $\mathrm{pH}$ is dictated by the solubility of the QDs when capped with DHLA. Further, it is well known that even small changes in assay format such as relative concentration, $\mathrm{pH}$ or salt concentration can dramatically alter activity kinetics [51, 52], thus it is hard to compare the assay data and activity collected here to that published in other reports. However, it appears that, in general, the amount of substrate utilized and minimal amount of enzyme detected along with assay time is far less $(>1$ order of magnitude for substrate concentration) than for reports using the same enzymes [54]. This strongly suggests that the QD size and self-assembled protein nanostructure do not interfere with proteolytic activity, at least for the enzymes tested here. The combination of the unique QD stability and the photophysical properties mentioned earlier along with access to higher sensitivity are all desirable attributes in any proteolytic assay format.

Finally, such QD-protein substrates may be directly applicable in assays where monitoring of nonspecific proteolysis is important such as during DNA preparation $[47,48]$. Other dye-labeled biological molecules such as peptides, DNA, RNA, or aptamers that are responsive to enzymes, drugs, or other chemicals can be easily adapted to this format and indeed a few preliminary qualitative enzymatic studies using QD-substrates have been reported, including a QD-sensor for monitoring lactamase activity associated with antibiotic resistance [55-58]. With the large number of putative proteases in the human genome $(\sim 560)$ as well as those utilized by pathogens, many will require intact protein substrates for recognition and cleavage/digestion [14]. The QD-protein conjugates described here provide a viable architecture to detect protein-digestion activity using FRET for signal transduction $[1,2]$.

\section{ACKNOWLEDGMENTS}

The authors acknowledge NRL, the Office of Naval Research and the Army Research Office/DTRA for financial support. Aaron R. Clapp was supported by a National Research Council Fellowship through NRL. The authors also gratefully acknowledge Dr. Hedi Mattoussi, NRL, for providing the luminescent quantum dots utilized in this study.

\section{REFERENCES}

[1] X. S. Puente and C. López-Otín, "A genomic analysis of rat proteases and protease inhibitors," Genome Research, vol. 14, no. 4, pp. 609-622, 2004.

[2] X. S. Puente, L. M. Sánchez, C. M. Overall, and C. LópezOtín, "Human and mouse proteases: a comparative genomic approach," Nature Reviews Genetics, vol. 4, no. 7, pp. 544-558, 2003.

[3] N. A. Thornberry, T. A. Rano, E. P. Peterson, et al., "A combinatorial approach defines specificities of members of the caspase family and granzyme B: functional relationships established for key mediators of apoptosis," The Journal of Biological Chemistry, vol. 272, no. 29, pp. 17907-17911, 1997.

[4] G. M. Cohen, "Caspases: the executioners of apoptosis," Biochemical Journal, vol. 326, part 1, pp. 1-16, 1997.

[5] P. Vihinen, R. Ala-Aho, and V.-M. Kähäri, "Matrix metalloproteinases as therapeutic targets in cancer," Current Cancer Drug Targets, vol. 5, no. 3, pp. 203-220, 2005.

[6] R. Ala-Aho and V.-M. Kähäri, "Collagenases in cancer," Biochimie, vol. 87, no. 3-4, pp. 273-286, 2005.

[7] M. M. Handsley and D. R. Edwards, "Metalloproteinases and their inhibitors in tumor angiogenesis," International Journal of Cancer, vol. 115, no. 6, pp. 849-860, 2005.

[8] I. Richard, "The genetic and molecular bases of monogenic disorders affecting proteolytic systems," Journal of Medical Genetics, vol. 42, no. 7, pp. 529-539, 2005.

[9] Y. Wu, X. Wang, X. Liu, and Y. Wang, "Data-mining approaches reveal hidden families of proteases in the genome of malaria parasite," Genome Research, vol. 13, no. 4, pp. 601616, 2003.

[10] F. Shao, P. M. Merritt, Z. Bao, R. W. Innes, and J. E. Dixon, "A Yersinia effector and a Pseudomonas avirulence protein define a family of cysteine proteases functioning in bacterial pathogenesis," Cell, vol. 109, no. 5, pp. 575-588, 2002.

[11] T. Imamura, "The role of gingipains in the pathogenesis of periodontal disease," Journal of Periodontology, vol. 74, no. 1, pp. 111-118, 2003.

[12] K. Anand, J. Ziebuhr, P. Wadhwani, J. R. Mesters, and R. Hilgenfeld, "Coronavirus main proteinase $\left(3 \mathrm{CL}^{\text {pro }}\right)$ structure: basis for design of anti-SARS drugs," Science, vol. 300, no. 5626, pp. 1763-1767, 2003.

[13] P. L. Richardson, "The determination and use of optimized protease substrates in drug discovery and development," Current Pharmaceutical Design, vol. 8, no. 28, pp. 2559-2581, 2002.

[14] T. Nagai and A. Miyawaki, "A high-throughput method for development of FRET-based indicators for proteolysis," Biochemical and Biophysical Research Communications, vol. 319, no. 1, pp. 72-77, 2004. 
[15] N. P. Mahajan, D. C. Harrison-Shostak, J. Michaux, and B. Herman, "Novel mutant green fluorescent protein protease substrates reveal the activation of specific caspases during apoptosis," Chemistry \&amp; Biology, vol. 6, no. 6, pp. 401409, 1999.

[16] S. M. Rodems, B. D. Hamman, C. Lin, et al., "A FRET-based assay platform for ultra-high density drug screening of protein kinases and phosphatases," ASSAY and Drug Development Technologies, vol. 1, no. 1, pp. 9-19, 2002.

[17] S. Kumar, C. R. Hanning, M. R. Brigham-Burke, et al., "Interleukin-1F7b (IL-1H4/IL-1F7) is processed by caspase-1 and mature IL-1F7b binds to the IL-18 receptor but does not induce IFN- $\gamma$ production," Cytokine, vol. 18, no. 2, pp. 61-71, 2002.

[18] N. A. Thornberry, H. G. Bull, J. R. Calaycay, et al., "A novel heterodimeric cysteine protease is required for interleukin- $1 \beta$ processing in monocytes," Nature, vol. 356, no. 6372, pp. 768774, 1992.

[19] J. R. Lakowicz, Principles of Fluorescence Spectroscopy, Springer, New York, NY, USA, 2006.

[20] D. Gerion, W. J. Parak, S. C. Williams, D. Zanchet, C. M. Micheel, and A. P. Alivisatos, "Sorting fluorescent nanocrystals with DNA," Journal of the American Chemical Society, vol. 124, no. 24, pp. 7070-7074, 2002.

[21] E. R. Goldman, A. R. Clapp, G. P. Anderson, et al., "Multiplexed toxin analysis using four colors of quantum dot fluororeagents," Analytical Chemistry, vol. 76, no. 3, pp. 684$688,2004$.

[22] I. L. Medintz, H. T. Uyeda, E. R. Goldman, and H. Mattoussi, "Quantum dot bioconjugates for imaging, labelling and sensing," Nature Materials, vol. 4, no. 6, pp. 435-446, 2005.

[23] A. R. Clapp, I. L. Medintz, J. M. Mauro, B. R. Fisher, M. G. Bawendi, and H. Mattoussi, "Fluorescence resonance energy transfer between quantum dot donors and dye-labeled protein acceptors," Journal of the American Chemical Society, vol. 126, no. 1, pp. 301-310, 2004.

[24] A. R. Clapp, I. L. Medintz, H. T. Uyeda, et al., "Quantum dotbased multiplexed fluorescence resonance energy transfer," Journal of the American Chemical Society, vol. 127, no. 51, pp. 18212-18221, 2005.

[25] I. L. Medintz, A. R. Clapp, H. Mattoussi, E. R. Goldman, B. Fisher, and J. M. Mauro, "Self-assembled nanoscale biosensors based on quantum dot FRET donors," Nature Materials, vol. 2, no. 9, pp. 630-638, 2003.

[26] F. Patolsky, R. Gill, Y. Weizmann, T. Mokari, U. Banin, and I. Wiliner, "Lighting-up the dynamics of telomerization and DNA replication by CdSe-ZnS quantum dots," Journal of the American Chemical Society, vol. 125, no. 46, pp. 13918-13919, 2003.

[27] E. R. Goldman, I. L. Medintz, J. L. Whitley, et al., "A hybrid quantum dot-antibody fragment fluorescence resonance energy transfer-based TNT sensor," Journal of the American Chemical Society, vol. 127, no. 18, pp. 6744-6751, 2005.

[28] C.-Y. Zhang and L. W. Johnson, "Quantum-dot-based nanosensor for RRE IIB RNA-Rev peptide interaction assay," Journal of the American Chemical Society, vol. 128, no. 16, pp. 5324-5325, 2006.

[29] C.-Y. Zhang, H.-C. Yeh, M. T. Kuroki, and T.-H. Wang, "Single-quantum-dot-based DNA nanosensor," Nature Materials, vol. 4, no. 11, pp. 826-831, 2005.

[30] A. R. Clapp, I. L. Medintz, and H. Mattoussi, "Förster resonance energy transfer investigations using quantum-dot fluorophores," ChemPhysChem, vol. 7, no. 1, pp. 47-57, 2006.
[31] I. L. Medintz, A. R. Clapp, F. M. Brunel, et al., "Proteolytic activity monitored by fluorescence resonance energy transfer through quantum-dot-peptide conjugates," Nature Materials, vol. 5, no. 7, pp. 581-589, 2006.

[32] C. B. Murray, C. R. Kagan, and M. G. Bawendi, "Synthesis and characterization of monodisperse nanocrystals and closepacked nanocrystal assemblies," Annual Review of Materials Science, vol. 30, pp. 545-610, 2000.

[33] L. Qu, Z. A. Peng, and X. Peng, "Alternative routes toward high quality CdSe nanocrystals," Nano Letters, vol. 1, no. 6, pp. 333337, 2001.

[34] M. A. Hines and P. Guyot-Sionnest, "Synthesis and characterization of strongly luminescing ZnS-capped CdSe nanocrystals," Journal of Physical Chemistry, vol. 100, no. 2, pp. 468471, 1996.

[35] H. Mattoussi, J. M. Mauro, E. R. Goldman, et al., "Selfassembly of CdSe-ZnS quantum dot bioconjugates using an engineered recombinant protein," Journal of the American Chemical Society, vol. 122, no. 49, pp. 12142-12150, 2000.

[36] B. O. Dabbousi, J. Rodriguez-Viejo, F. V. Mikulec, et al., "(CdSe) ZnS core-shell quantum dots: synthesis and characterization of a size series of highly luminescent nanocrystallites," Journal of Physical Chemistry B, vol. 101, no. 46, pp. 94639475, 1997.

[37] E. R. Goldman, I. L. Medintz, A. Hayhurst, et al., "Selfassembled luminescent $\mathrm{CdSe}-\mathrm{ZnS}$ quantum dot bioconjugates prepared using engineered poly-histidine terminated proteins," Analytica Chimica Acta, vol. 534, no. 1, pp. 63-67, 2005.

[38] I. L. Medintz, E. R. Goldman, M. E. Lassman, and J. M. Mauro, "A fluorescence resonance energy transfer sensor based on maltose binding protein," Bioconjugate Chemistry, vol. 14, no. 5, pp. 909-918, 2003.

[39] D. A. Harris, "Spectrophotometric assays," in Spectrophotometry and Spectrofluorimetry, pp. 49-90, IRL Press, Washington, DC, USA, 1987.

[40] K. E. Sapsford, T. Pons, I. L. Medintz, et al., "Kinetics of metalaffinity driven self-assembly between proteins or peptides and CdSe-ZnS quantum dots," Journal of Physical Chemistry C, vol. 111, no. 31, pp. 11528-11538, 2007.

[41] T. Pons, I. L. Medintz, X. Wang, D. S. English, and H. Mattoussi, "Solution-phase single quantum dot fluorescence resonant energy transfer sensing," Journal of the American Chemical Society, vol. 128, no. 47, pp. 15324-15331, 2006.

[42] T. Pons, H. T. Uyeda, I. L. Medintz, and H. Mattoussi, "Hydrodynamic dimensions, electrophoretic mobility, and stability of hydrophilic quantum dots," Journal of Physical Chemistry B, vol. 110, no. 41, pp. 20308-20316, 2006.

[43] I. L. Medintz, J. H. Konnert, A. R. Clapp, et al., "A fluorescence resonance energy transfer-derived structure of a quantum dot-protein bioconjugate nanoassembly," Proceedings of the National Academy of Sciences of the United States of America, vol. 101, no. 26, pp. 9612-9617, 2004.

[44] B. A. Springer and S. G. Sligar, "High-level expression of sperm whale myoglobin in Escherichia coli," Proceedings of the National Academy of Sciences of the United States of America, vol. 84, no. 24, pp. 8961-8965, 1987.

[45] A. J. Sharff, L. E. Rodseth, and F. A. Quiocho, "Refined 1.8Åstructure reveals the mode of binding of $\beta$-cyclodextrin to the maltodextrin binding-protein," Biochemistry, vol. 32, no. 40, pp. 10553-10559, 1993.

[46] L. C. Alves, R. L. Melo, S. J. Sanderson, et al., " $S_{1}$ subsite specificity of a recombinant cysteine proteinase, $\mathrm{CPB}$, of Leishmania mexicana compared with cruzain, human cathepsin $\mathrm{L}$ and papain using substrates containing non-natural basic 
amino acids," European Journal of Biochemistry, vol. 268, no. 5, pp. 1206-1212, 2001.

[47] J. Sambrook, E. F. Fritsch, and T. Maniatis, Molecular Cloning: A Laboratory Manual, Cold Spring Harbor Laboratory Press, Woodbury, NY, USA, 2nd edition, 1989.

[48] D. Petsch, W.-D. Deckwer, and F. B. Anspach, "Proteinase $\mathrm{K}$ digestion of proteins improves detection of bacterial endotoxins by the Limulus amebocyte lysate assay: application for endotoxin removal from cationic proteins," Analytical Biochemistry, vol. 259, no. 1, pp. 42-47, 1998.

[49] B. R. Rabin and P. W. Trown, "Inhibition of carboxydismutase by iodoacetamide," Proceedings of the National Academy of Sciences of the United States of America, vol. 51, no. 3, pp. 497501, 1964.

[50] S. Jana and J. K. Deb, "Molecular targets for design of novel inhibitors to circumvent aminoglycoside resistance," Current Drug Targets, vol. 6, no. 3, pp. 353-361, 2005.

[51] M. Dixon, "The determination of enzyme inhibitor constants," Biochemical Journal, vol. 55, part 1, pp. 170-171, 1953.

[52] A. C. Bowden, Fundamentals of Enzyme Kinetics, Portland Press, London, UK, 1995.

[53] K. E. Sapsford, T. Pons, I. L. Medintz, and H. Mattoussi, "Biosensing with luminescent semiconductor quantum dots," Sensors, vol. 6, no. 8, pp. 925-953, 2006.

[54] J. Bajorath, W. Saenger, and G. P. Pal, "Autolysis and inhibition of proteinase $\mathrm{K}$, a subtilisin-related serine proteinase isolated from the fungus Tritirachium album Limber," Biochimica et Biophysica Acta, vol. 954, pp. 176-182, 1988.

[55] C. Xu, B. Xing, and J. Rao, "A self-assembled quantum dot probe for detecting $\beta$-lactamase activity," Biochemical and Biophysical Research Communications, vol. 344, no. 3, pp. 931935, 2006.

[56] E. Chang, J. S. Miller, J. Sun, et al., "Protease-activated quantum dot probes," Biochemical and Biophysical Research Communications, vol. 334, no. 4, pp. 1317-1321, 2005.

[57] L. Shi, V. De Paoli, N. Rosenzweig, and Z. Rosenzweig, "Synthesis and application of quantum dots FRET-based protease sensors," Journal of the American Chemical Society, vol. 128, no. 32, pp. 10378-10379, 2006.

[58] L. Shi, N. Rosenzweig, and Z. Rosenzweig, "Luminescent quantum dots fluorescence resonance energy transfer-based probes for enzymatic activity and enzyme inhibitors," Analytical Chemistry, vol. 79, no. 1, pp. 208-214, 2007. 

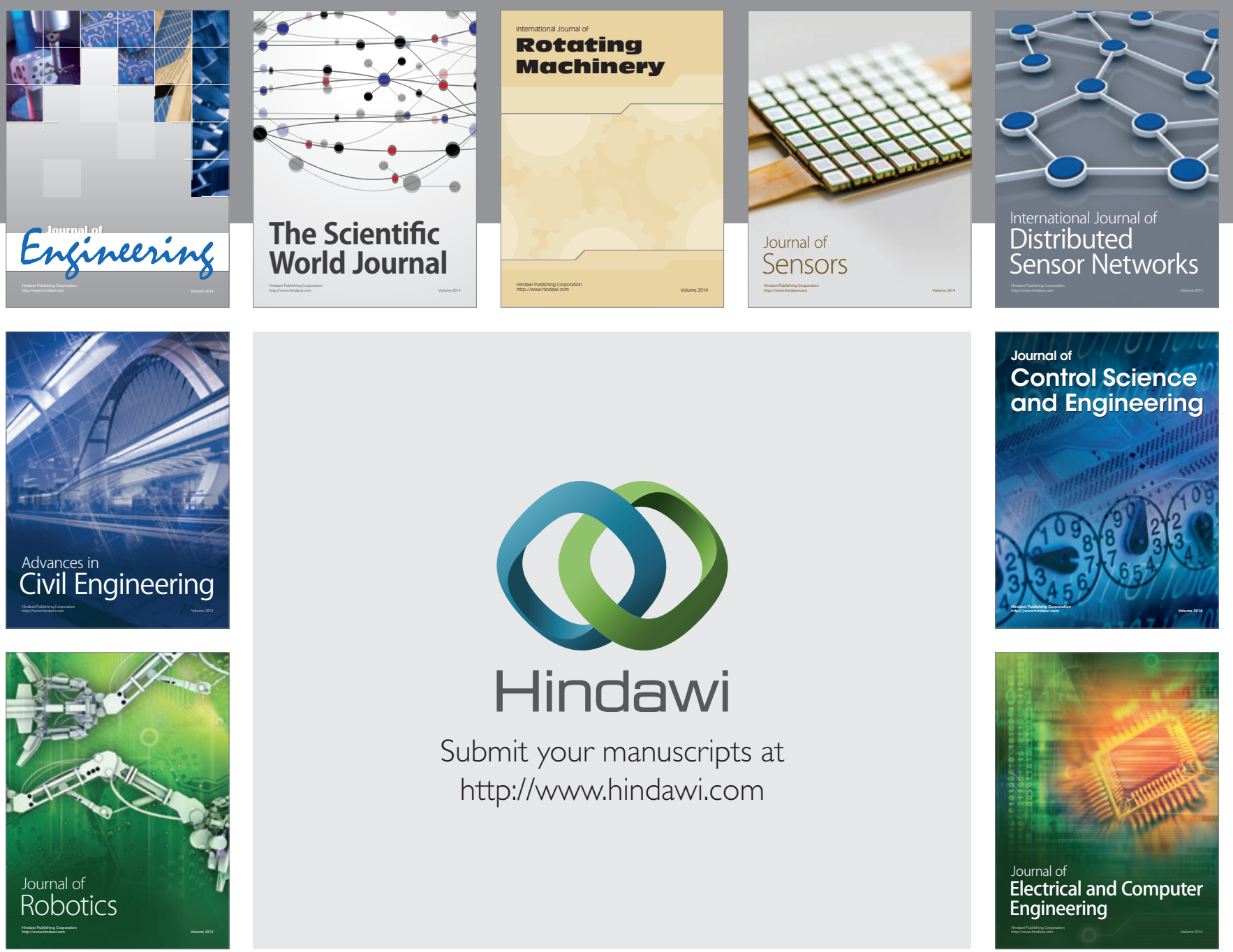

Submit your manuscripts at

http://www.hindawi.com
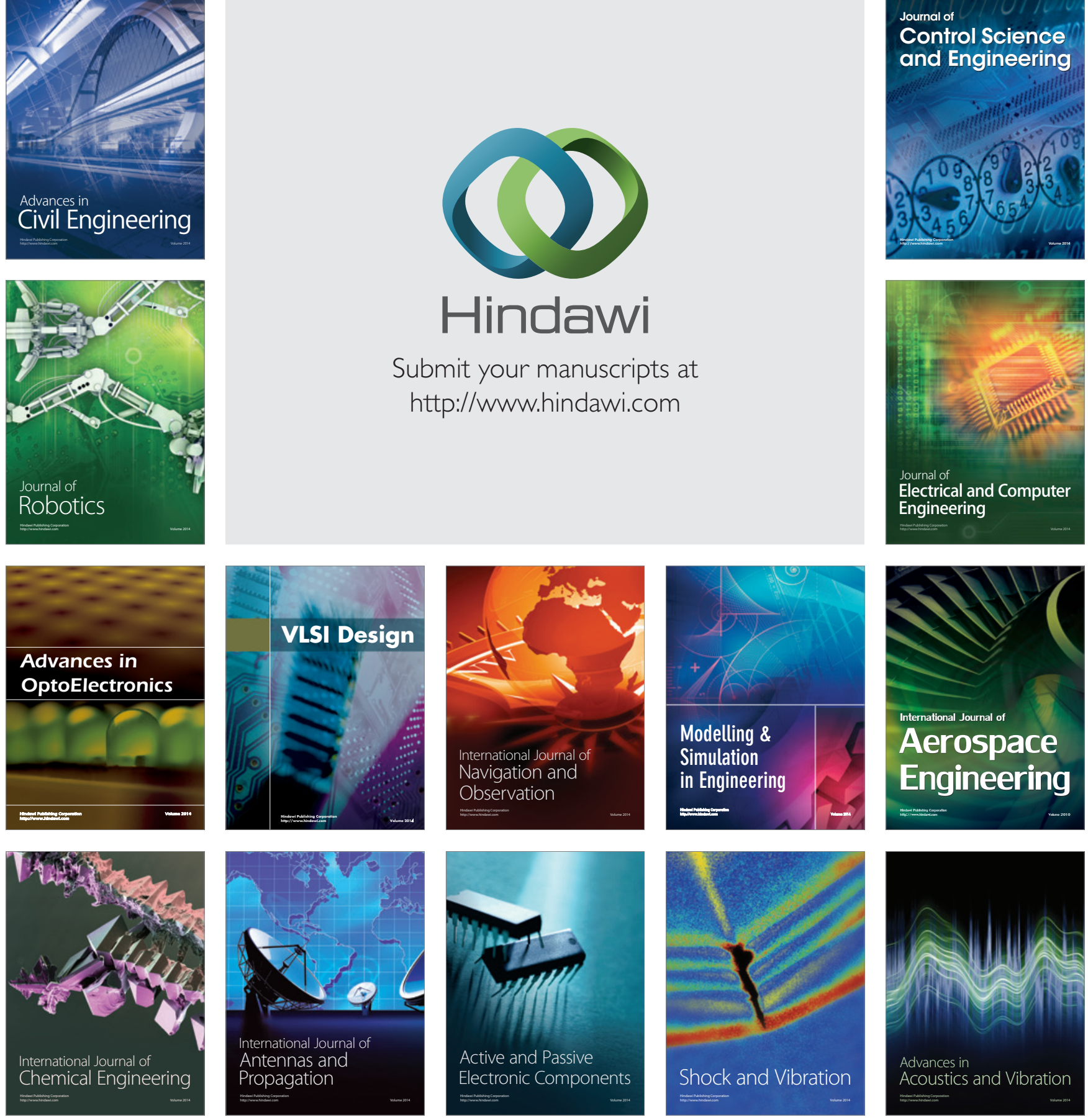